\title{
Effects of the Shape and Size of Irregular Particles on Specific Breakage Energy under Drop Weight Impact
}

\author{
Deqing Gan, ${ }^{1}$ Feng Gao $\triangle{ }^{1},{ }^{1}$ Yunpeng Zhang, ${ }^{1}$ Jinxia Zhang, ${ }^{1}$ Fusheng Niu, ${ }^{1}$ and Ze Gan ${ }^{2}$ \\ ${ }^{1}$ College of Mining Engineering, North China University of Science and Technology, Tangshan, Hebei 063210, China \\ ${ }^{2}$ Department of Science and Technology, North China University of Science and Technology, Tangshan, Hebei 063210, China
}

Correspondence should be addressed to Feng Gao; gao7975498@163.com

Received 2 April 2019; Revised 13 May 2019; Accepted 22 May 2019; Published 4 June 2019

Academic Editor: Yuri S. Karinski

Copyright (c) 2019 Deqing Gan et al. This is an open access article distributed under the Creative Commons Attribution License, which permits unrestricted use, distribution, and reproduction in any medium, provided the original work is properly cited.

Particle shape and size are main factors influencing particle breakage. Single-particle breakage tests were conducted on irregular magnetite ore using modified drop weight impact equipment to analyze the effect of shape and size on specific breakage energy. A method to measure the effective breakage energy is presented. Ore particles with different sphericities and different sizes were broken into several fragments with differing impact energies in the tests. Experimental studies indicate that the shape of particles significantly influences the impact loading mode and breakage progress; the specific breakage energy has an obvious relationship with the sphericity and the initial size. The specific breakage energy decreases with larger initial loading area. The particle needs less specific breakage energy if the shape or placement state is more conducive to tensile fracture. There is an increase in specific breakage energy corresponding to an increase in particle sphericity with fixed initial size range. With the increase in the initial size of the particle, the specific breakage energy decreases with fixed sphericity range, which presents a power function with the exponent -0.5 . The comprehensive relationship between specific breakage energy, particle sphericity, and initial size was established, showing that the input power of the crushing machinery and the optimization of crushing technology should be performed with consideration of the influence of particle shape and initial size to reduce specific energy consumption and improve energy efficiency.

\section{Introduction}

Ore breakage is one of the main concerns in the mine production process; that is, particle size is reduced and minerals are disintegrated by energy. The amount of energy used for ore breakage is much smaller than that consumed in the motion of the ore and machine and the heat generated by friction [1]. The energy needed to break a unit mass of ore is defined as specific breakage energy, which has a close relationship with ore properties. The parameters of crushing machinery and technology could be designed reasonably if the specific breakage energy is ascertained; thus, it is important to research the relationship between specific breakage energy and ore properties.

Single-particle breakage under impact has been a common method of studying ore breakage because it can reduce the frictional dissipation to the lowest value and void the energy loss caused by particle interaction. Several kinds of test apparatuses of single-particle impact breakage have been developed, such as the drop weight tester (DWT), pendulum tester, rotary breakage tester in Julius Kruttschnitt Mineral Research Centre (JKMRC), Hopkinson bar, and others $[2,3]$. Compared with other devices, the DWT has the best flexibility for adjustment of energy parameters, including the hammer mass and impact height or velocity, and it is easy to use for experiments without the limitation of the shape and initial size. In addition, the DWT has a coincident strain-rate range with mechanical breakage, so it is popular for testing ore breakage characteristics $[2,4-7]$. One of the main functions of DWT tests is to obtain an ore competence indicator $(A \cdot b)$, but this requires 15 experiments with five size fractions of ore and three energy levels in the test standardized by the Julius Kruttschnitt Mineral Research Centre [8], which results in a significant 
workload and is time consuming in preparing more than 360 particles for one test. If the theoretical relationship between specific breakage energy and ore properties is ascertained, it is possible to predict the energy needed to crush a particle and calculate the specific breakage energy of ore in different size ranges. Then, the number of tests could be reduced. As with a certain kind of ore, the shape and size are the main factors influencing specific energy and breakage results in individual impact tests [7]. During ore processing, the particles are irregular with greatly varying shapes and initial sizes, so the difference between the experimental values and virtual values of breakage energy can be reduced to carry out individual impact tests using irregular particles, which helps improve the accuracy of the design of technology parameters. The particle shape affects the loading modes and breakage process, resulting in the change of breakage characteristics and energy characteristics $[9,10]$. The impact breakage characteristics of nonspherical coal were studied by Zheng et al. [11] using discrete element method (DEM) simulation with the parallel-bond model of primary particles. The results demonstrate that with increasing coal sphericity, the maximum force and breakage ratio increase under face loading but decrease under edge loading or vertex loading and that a small change in coal sphericity can cause obvious variations in breakage patterns. Similar results were obtained by Liu et al. [12], who used a granular dynamics model containing the adhesive option with no plastic deformation in discrete element simulations to study the breakage of spherical, cuboidal, and cylindrical agglomerates. This study showed that the breakage ratios approach 0.32 under cuboidal face, cylindrical end, and cylindrical side impacts and that the breakage ratios approach 0.18 under cuboidal edge, cuboidal corner, and cylindrical corner impacts; the authors insisted that the reason for these phenomena is that the difference in loading area makes the difference in the wall forces that work on agglomerates. According to the investigation of Afshar et al. [13], the breakage strength of bulky construction particles (sphericity varies from 0.8 to 0.84 ) is higher than that of elongated construction particles (sphericity varies from 0.7 to 0.74 ); thus, the bulky particles have a lower degree of breakage under the same compression conditions and they consume a higher energy density to have the same fragmentation results as the elongated particles. In a recent study by Yan et al. [14], it was observed that the difference in rock shape and impact angle can result in a great difference in loading mode and breakage results for reinforced concrete slabs. Yan et al. [14] used an ellipsoid to describe a falling rock approximately, and impact angles were defined as the angles between the longest axis and the impact direction, and they found that the impact parameters increase with rock sphericity if the impact angles are $0^{\circ}$ and $45^{\circ}$, but the trend is contrary if the impact angle is $90^{\circ}$. The impact parameters include the maximum impact force, impact pulse, and displacement of concrete. It can be seen from the previous literature that the variation in shape can cause a change in particle breakage characteristics; we believe that it affects the specific energy that is required for breakage as well. Although studies on the effect of shape on breakage energy are scarce, this assumption was demonstrated by Unland and Al-Khasawneh [15] in their investigation of the shape effect on breakage energy and energy efficiency with single-particle tests on limestone. They found that the specific breakage energy of cuboidal particles varies from 2.4 to $2.5 \mathrm{~J} / \mathrm{g}$, which is approximately 1.5 times larger than that of acicular and plate-shaped particles and that the area of new surface produced by unit breakage energy increases with the increase in elongation and flatness of the initial particles. The drop weight impact tests conducted by Norraziah et al. [16] also reflected that flaky pegmatite needs less energy than equidimensional pegmatite to be fragmented at the same degree.

Apart from particle shape, the particle size has significant influence on breakage behavior. The established energy models include the relationship between specific energy and particle size [17-21]; that is, the specific energy decreases with increasing particle size. However, the total input energy per unit mass is used as the specific breakage energy here, which is greater than the virtual specific energy that is actually consumed during crushing. The change regulation of specific energy with particle size and the question of specific energy were validated by Tavares [5] who conducted singleparticle breakage tests under drop weight impact. The later study conducted by Banini [22] reported the size effect on particle breakage with eight types of ore and concluded that because of the higher crack density in large initial particles, the specific breakage energy of large initial particles is lower than that of small initial particles.

The shape and size are important physical properties of particles; in past research, the influences of shape and size on particle breakage were analyzed, respectively, and studies on shape effect gave priority to qualitative discussion. However, there are few investigations on the comprehensive effects of irregular particle shape and size on specific breakage energy, and no quantitative relationships among specific breakage, particle shape, and initial size were found in the past, which makes it difficult to guide ore dressing in plants considering the combined effects of particle shape and size. In the present study, the influence of particle shape and size on specific breakage energy and the relationship among them are investigated. For this purpose, single-particle impact breakage tests on irregular magnetite ore particles were carried out with the modified DWT that is used to measure the effective breakage energy, assisted by use of a high-speed camera that recorded the ore fracture process.

\section{Materials and Methods}

2.1. Magnetite Ore. Irregular magnetite ore was chosen as the experimental material, and the samples were obtained from Shuichang Open Pit of Shoudu Steel Company in North China. The uniaxial compressive strength of magnetite ore varied from 90.5 to $124.1 \mathrm{MPa}$, the tensile strength varied from 8.0 to $11.3 \mathrm{MPa}$, the average density was $3.26 \times 10^{3} \mathrm{~kg} / \mathrm{m}^{3}$, and the average grade of the magnetic iron was $28.03 \%$. The samples were washed and air-dried; the mass of the dry samples was 55-1082 g (Figure 1). 


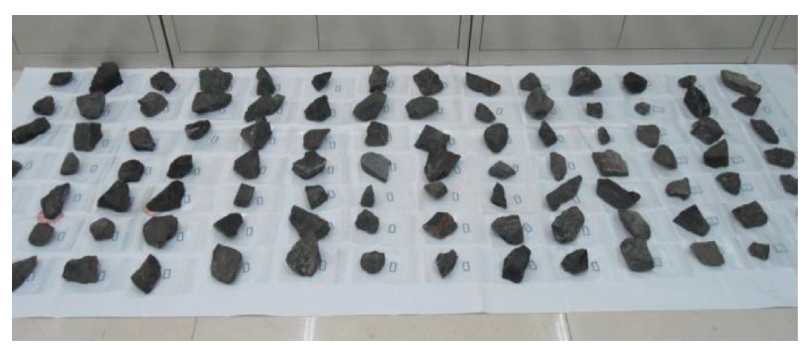

FiguRE 1: Irregular magnetite ore samples.

\subsection{Material Parameters}

2.2.1. Shape Parameter. Sphericity is a common shape parameter used to describe the space morphology of irregular particles $[10,11,13,14]$. The formula of sphericity is given by

$$
\psi=\sqrt[3]{\frac{l h}{L^{2}}},
$$

where $\psi$ is the sphericity of the particle, $l$ the maximum width, $h$ the maximum thickness, and $L$ the maximum length. The length, width, and thickness are easily measured as basic sizes to estimate particle shape $[23,24]$. The relationship of the three size parameters is $L \geq l \geq h$, and their direction is perpendicular to each other in space.

Sphericity is defined as the proximity extent to the sphere; the sphericity of a particle is no greater than 1 -the smaller the sphericity is, the closer the particle shape is to flaky, acicular, or long columnar. The sphericity distribution of magnetite ore is subject to standard normal distribution, which is shown in Figure 2. The main range of ore sphericity is from 0.45 to $0.9 ; 98.2 \%$ of ore particles showed sphericities under 0.825 .

2.2.2. Size Parameter. The equivolumetric sphere diameter is adopted as the equivalent size of irregular magnetite ore, which is calculated with the volume of ore, via the following method:

$$
d_{\mathrm{v}}=\left(\frac{6 V}{\pi}\right)^{1 / 3}
$$

where $d_{\mathrm{v}}$ is the equivalent size of irregular magnetite ore $(\mathrm{mm})$ and $V$ the volume of irregular magnetite ore $\left(\mathrm{mm}^{3}\right)$. The volume of irregular magnetite ore is measured with the drainage method. The range of equivalent size is 23.7$86.6 \mathrm{~mm}$. The equivalent size distribution is calculated as shown in Figure 3.

2.3. Apparatus. Conventional DWT tests take gravitational potential energy or impact energy as breakage energy [3, 16, 25, 26, 27]. However, some energy could be transmitted into the base of the tester when the hammer impacts the particle, and the rebounding or downthrusting of the hammer can consume some energy as well, so the virtual energy used for particle breakage is less than the impact energy. King and Bourgeois [19] and Tavares and King [7] designed a new drop weight impact device that is called the

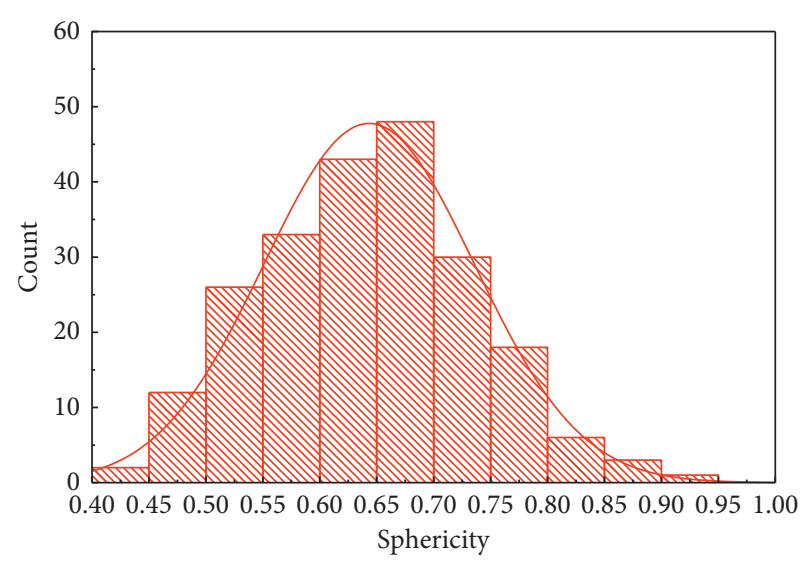

FIgURE 2: Sphericity distribution of magnetite ore.

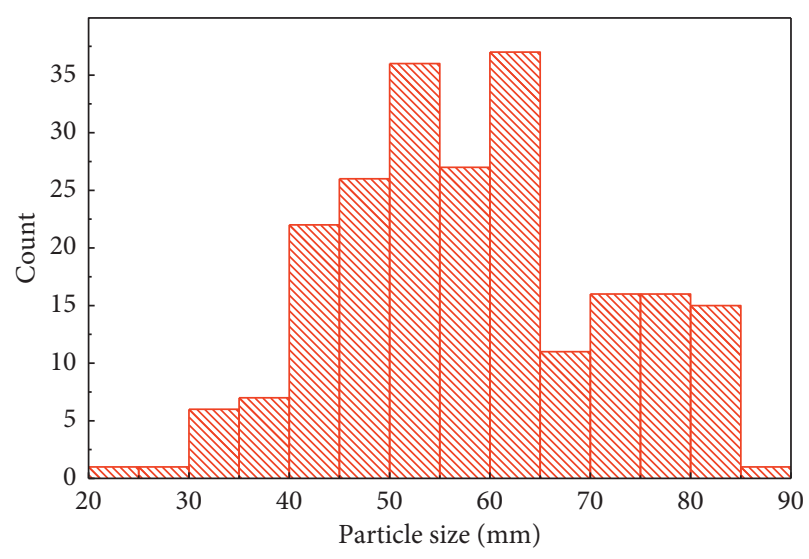

FIgURE 3: Equivalent size distribution of magnetite ore.

ultrafast load cell (UFLC). The UFLC rod in this device is $5 \mathrm{~m}$ long to ensure that the reflected wave from the bottom does not meet the original wave at the position of strain gauges. However, this makes it difficult to be installed in the laboratory, and it seems to be difficult to carry out impact tests if the particle size is much larger than the diameter of the UFLC rod.

Benjamin [28] put forward the calculation methods of effective breakage energy for columnar particles based on the UFLC. However, the ore shape in practice is much different from a column, and the particle size in practice is much larger than that in the experiments by Tavares and King [7] and Benjamin [28]. The effective breakage energy of ore particles of any shape with a wide range of sizes has not yet been accurately measured or calculated. We changed the structure of the conventional DWT to measure the absorbed energy, which is taken as approximately the effective breakage energy. The modified DWT is shown in Figure 4. Several industrial springs (11) are set between the base (10) and foundation (13). A displacement meter (7) is fixed at one side of the base. A force sensor (9) is installed between the baseplate (8) and the base (10).

The impact energy is changed by the adjustment drop height or the mass of the drop weight. When the drop weight impacts the sample, the energy transmitted into the base is converted into the initial kinetic energy of the base. The 


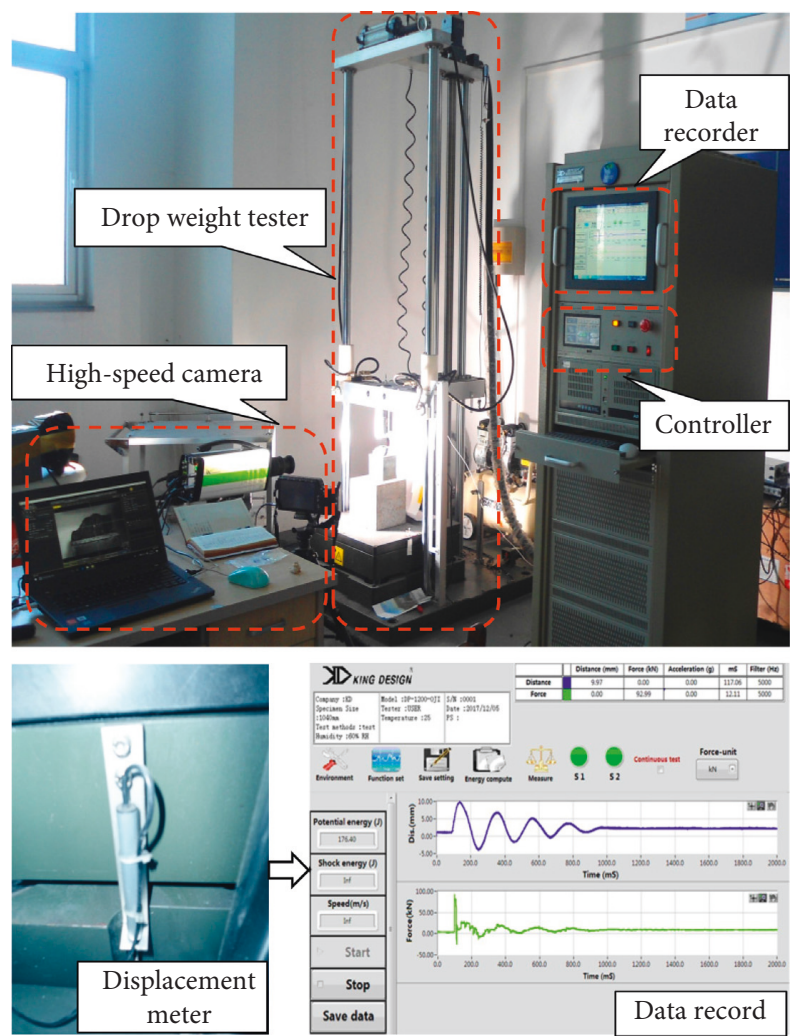

(a)

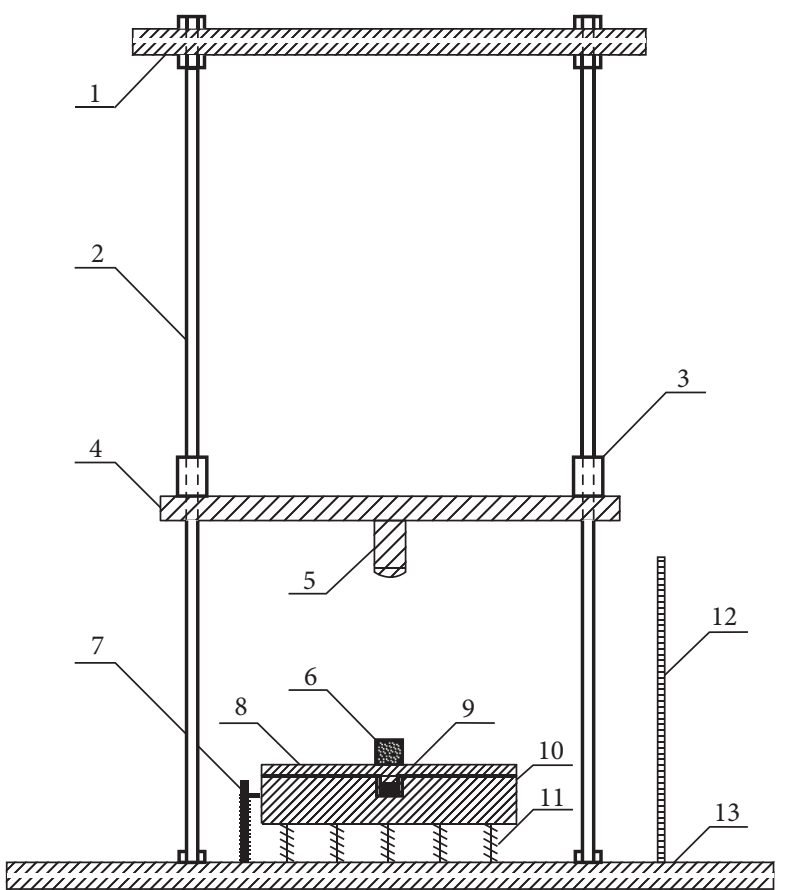

(b)

Figure 4: Experimental setup. (a) Experimental apparatus, including drop weight tester with controller and data recorder, high-speed camera, and a laptop. (b) Structure of drop weight tester: 1, crossbeam; 2, guide rod; 3, brake; 4, hammer beam; 5, hammerhead; 6, sample; 7 , displacement meter; 8 , baseplate; 9 , force sensor; 10, base; 11, industrial spring; 12 , ruler; 13 , foundation.

displacement meter measures the displacement of the base while it compresses the springs downward. The force is measured by the force sensor during impact; for the purpose of the present study, the measured results of force will be analyzed in future studies.

After the impact event, some impact energy could be retained as the kinetic energy of the drop weight if it rebounds or pitches down, which can be recorded with the high-speed camera (up to 7960 images/s with a resolution of $1920 \times 1080)$. After the rebounding of the drop weight, the brake system starts up to prevent a second impact. The effective breakage energy can be obtained by subtracting the initial kinetic energies of the base and the drop weight after impact, which is expressed as

$$
E_{\mathrm{a}}=E_{\mathrm{I}}-E_{\mathrm{dk}}-E_{\mathrm{cs}}
$$

where $E_{\mathrm{a}}$ is the breakage energy $(\mathrm{J}), E_{\mathrm{I}}$ the impact energy $(\mathrm{J})$, $E_{\mathrm{dk}}$ the initial kinetic energy of the base (J), and $E_{\mathrm{cs}}$ the initial kinetic energy of the drop weight after impact (J).

Before each test, the guide rods are cleaned with cleaning agent to ensure the guide rods are smooth enough to reduce the influence of frictional resistance as much as possible when the drop weight is released and falls along the guide rods under gravity. Thus, the impact energy equals the kinetic energy for free fall, which is given by

$$
E_{\mathrm{I}}=m_{\mathrm{c}} g h,
$$

where $m_{\mathrm{c}}$ is the mass of drop weight $(\mathrm{kg})$, $\mathrm{g}$ the acceleration due to gravity $\left(\mathrm{m} / \mathrm{s}^{2}\right)$, and $h$ the drop weight $(\mathrm{m})$.

The initial kinetic energy of the base and the work done by gravity on the base are converted to the elastic energy of springs, which can be expressed as follows:

$$
E_{\mathrm{dk}}+W_{\mathrm{dg}}=\Delta E_{\mathrm{e}} \text {, }
$$

where $W_{\mathrm{dg}}$ is the work done by gravity $(\mathrm{J})$ and $\Delta E_{\mathrm{e}}$ the change of elastic potential energy (J) that can be calculated with the measured data of the displacement meter, as given by

$$
\Delta E_{\mathrm{e}}=\frac{1}{2000} n K\left[\left(\Delta x+x_{0}\right)^{2}-x_{0}^{2}\right]
$$

where $n$ is the number of springs, $K$ the elasticity coefficient $(\mathrm{N} / \mathrm{mm}), \Delta x$ the maximum displacement that the base moves downward $(\mathrm{mm})$, and $x_{0}$ the initial deformation of the spring $(\mathrm{mm})$.

The equation for initial kinetic energy of the base is

$$
E_{\mathrm{dk}}=\Delta E_{\mathrm{e}}-m_{\mathrm{d}} g \Delta x
$$

where $m_{\mathrm{d}}$ is the mass of base $(\mathrm{kg})$.

The velocity of the hammer after impact can be monitored with the high-speed camera; then, the initial kinetic energy of the hammer after impact can be calculated with equation (8). If the velocity of the hammer after impact is zero, the value of $E_{\mathrm{cs}}$ should be zero: 


$$
E_{\mathrm{cs}}=\frac{1}{2} m_{\mathrm{c}} v^{2},
$$

where $v$ is the velocity of the hammer after impact $(\mathrm{m} / \mathrm{s})$. Substituting equations (4), (7), and (8) into equation (5), the equation of effective breakage energy is written as

$$
E_{\mathrm{a}}=m_{\mathrm{c}} g h-\frac{1}{2000} n K\left[\left(\Delta x+x_{0}\right)^{2}-x_{0}^{2}\right]+m_{\mathrm{d}} g \Delta x-\frac{1}{2} m_{\mathrm{c}} v^{2} .
$$

According to the definition, the formula for specific breakage energy can be given by

$$
\begin{aligned}
& e_{\mathrm{m}}=\frac{E_{\mathrm{a}}}{m}=\frac{m_{\mathrm{c}}}{m} g h-\frac{n K}{2000 m}\left[\left(\Delta x+x_{0}\right)^{2}-x_{0}^{2}\right]+\frac{m_{\mathrm{d}}}{m} g \Delta x \\
& -\frac{m_{\mathrm{c}} v^{2}}{2 m},
\end{aligned}
$$

where $e_{\mathrm{m}}$ is the specific breakage energy $(\mathrm{J} / \mathrm{kg})$ and $m$ the mass of the sample $(\mathrm{kg})$.

2.4. Validation of Modified DWT. A spring with known elastic coefficient $(42.84 \mathrm{~N} / \mathrm{mm})$ is chosen as the material for validation tests because the energy absorbed by the spring is totally converted into deformation energy that could be calculated using the deformation and elastic coefficient and the spring can be impacted repetitively. The absorbed energy at the time that maximum deformation occurs could be measured by the apparatus, and the maximum deformation energy could be calculated with equation (11). In seven separate groups of validation tests, the impact height was set as $40,60,80,100$, 125,135 , and $150 \mathrm{~mm}$; the mass of the drop weight was $50 \mathrm{~kg}$; and the maximum deformation of the spring was recorded with a high-speed camera (model number i-SPEED 716, iX Cameras, UK; the photographic speed was set to 7500 images/ s), as shown in Figure 5. Five or six impacts were done in each group of tests. The average maximum deformation energy and the corresponding average absorbed energy are compared in Figure 6(a), and the relationship between the two is fitted in Figure 6(b):

$$
E=5 \times 10^{-4} K \Delta x_{\max }^{2}
$$

where $E$ is the maximum deformation energy (J), $K$ the elastic coefficient $(K=42.84 \mathrm{~N} / \mathrm{mm})$, and $\Delta x_{\max }$ the maximum deformation of the spring $(\mathrm{mm})$.

It can be seen from Figure 6 that the average values of maximum deformation energy calculated with equation (11) are very close to the average values of the corresponding absorbed energy that is measured with the apparatus and that the difference ratio is only $4.9 \%$ between maximum deformation energy and corresponding absorbed energy, indicating that the absorbed energy calculated using the data from the modified apparatus is accurate. The absorbed energy is regarded as the effective breakage energy when crushing ore particles. The good agreement shows that the apparatus and equation (9) can be used to estimate the breakage energy satisfactorily.
2.5. Experimental Scheme. Single-particle breakage tests were carried out on irregular magnetite ore with the modified DWT. The mass of the drop weight is $50 \mathrm{~kg}$. The impact energy was controlled by adjusting the drop height. The displacement of the base was measured, and the motion state of the hammer, loading mode, and ore breakage process were recorded with the high-speed camera. The specific breakage energy was calculated with equation (10).

During the breakage process, the new surface area is proportional to the work done by the external force [29]. As with a certain particle, the more breakage energy is consumed, the larger the new surface, the greater the number of fragments, and the higher the ratio of kinetic energy of fragments in impact energy. To analyze the effect of shape and size on effective specific breakage energy, the ore samples were broken into several fragments with a small amount of fine particles having a mass ratio no larger than $10 \%$ of the mass of the initial particle. The fragmentation of particles was regarded as the first fracture in the study by Saeidi et al. [4], so it was not necessary to consider the mass of the fine particles in the analysis of test results. The results of experiments that had the same number of fragments $(n=3,4,5)$ were chosen to establish the quantitative relationship of effective specific breakage energy, ore sphericity, and equivalent size.

\section{Results and Discussion}

3.1. Breakage Results. The breakage results of irregular magnetite ore under one impact were divided into three types: the particle was not broken, the particle was broken into several fragments, or the particle was excessively broken into debris. The breakage results of the first and third types were irrelevant in the present study; the ratios of the two types are lower than $20 \%$ in all particles, so they were excluded from the analysis.

The number of fragments in the first fracture ranged from two to nine, and the probability of each fragment number is shown in Figure 7 with photographs of the fragments. The probabilities of three fragments, four fragments, and five fragments after impact breakage are $24.62 \%, 23.08 \%$, and $30.79 \%$, respectively; those of the others are low in the first fracture. The size $x_{1}$ before breakage is the equivolumetric sphere diameter of ore particles. The mass of each fragment is measured after impact; the equivolumetric sphere diameter is calculated with fragment mass and ore density, and the median size of the sieved particles served as the size of debris with a mass smaller than $3 \mathrm{~g}$. Then, the average fragment size $x_{2}$ was obtained using the method of weight mean. The sizes of ore particles and fragments are shown in Figure 8. According to the record of the high-speed camera, the hammer did not rebound after impact because the hammer mainly contacted the sample at a vertex, in a line, or at a small face initially, and then the contact mode changed to face mode because of the smashing of the contact part. The values of breakage energy of each particle are shown in Figure 9 according to the calculation with test data using equation (9). The specific breakage energy is defined as the breakage 


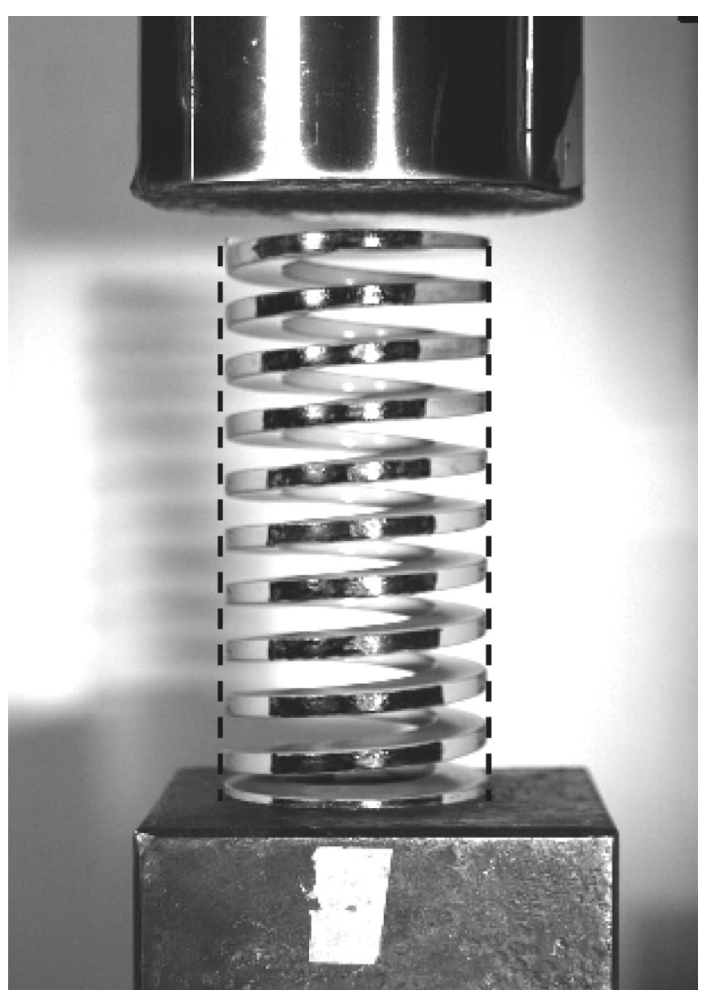

(a)

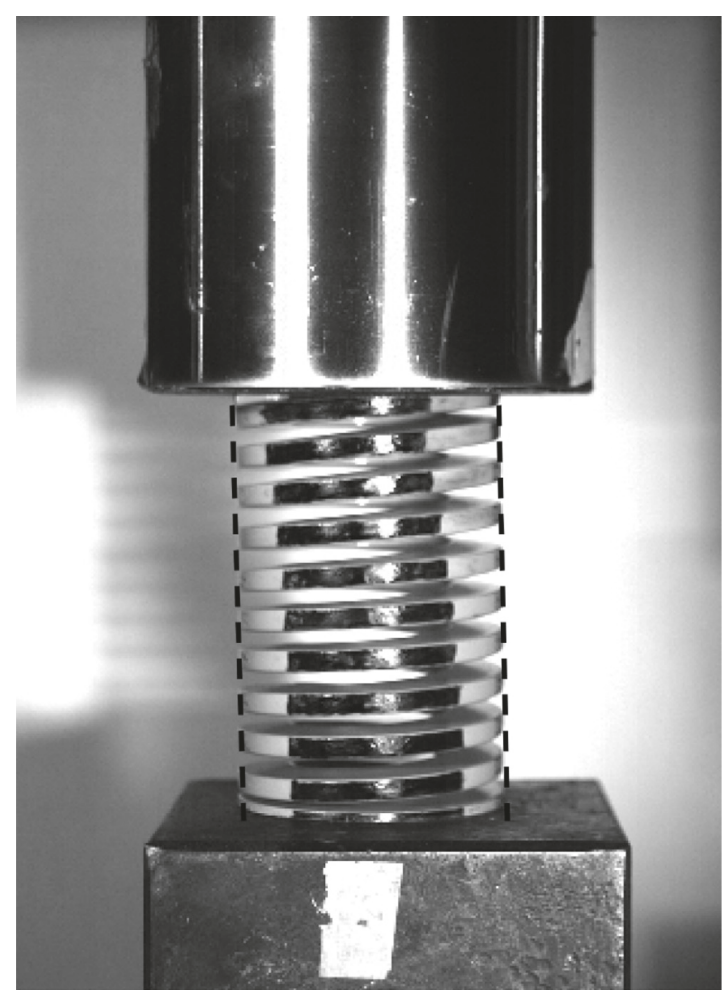

(b)

FIgURE 5: Deformation of spring under impact at height of $60 \mathrm{~mm}$ : (a) initial length of spring; (b) maximum deformation of spring.

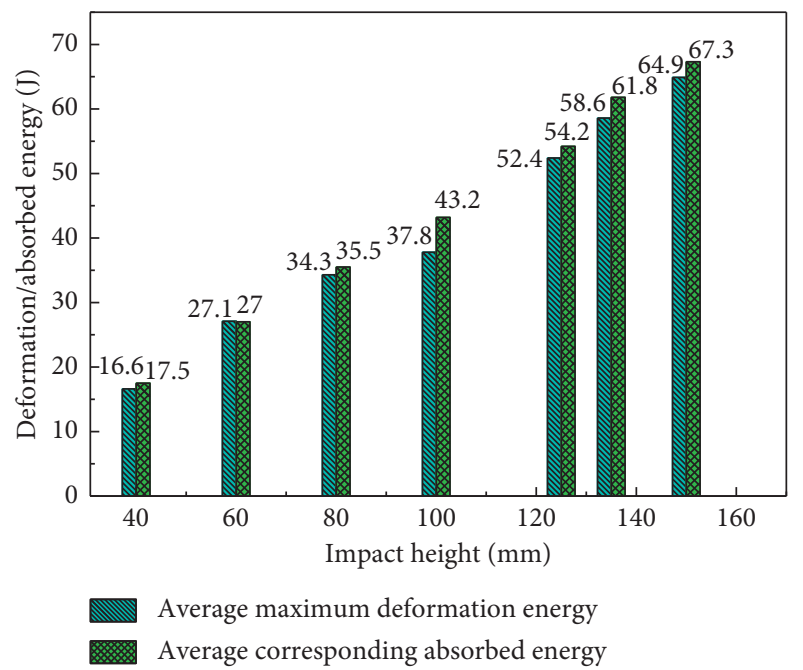

(a)

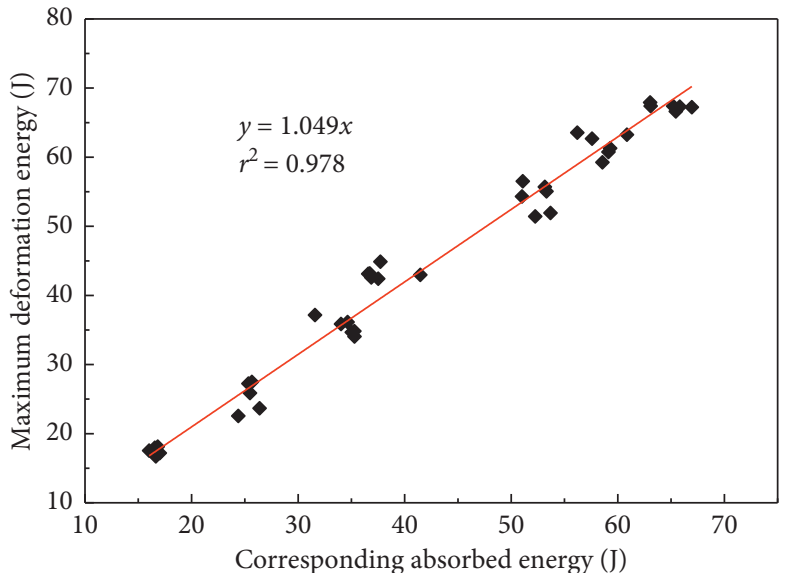

(b)

Figure 6: Maximum deformation energy and corresponding absorbed energy.

energy divided by particles mass, as shown in equation (10).

\subsection{Loading Mode and Specific Breakage Energy}

3.2.1. Loading Mode and Breakage Process. The loading modes and breakage processes of some typical samples are shown in Figure 10 and are similar to other samples. The mass of the sample in Figure 10(d) is $232 \mathrm{~g}$, and the masses of other samples in Figure 10 range from 256 to $265 \mathrm{~g}$. The upper end of the sample bore impact loading and the lower end bore the counterforce of baseplate.

In Figure 10(a), the upper end of the sample bore line loading and the lower end bore face loading. With the prolongation of acting time, sample SQ89 deflected, the upper contact area was smashed, and the contact area increased; the contact area of the lower end decreased, the fissile expanded from the lower end to the upper end, 


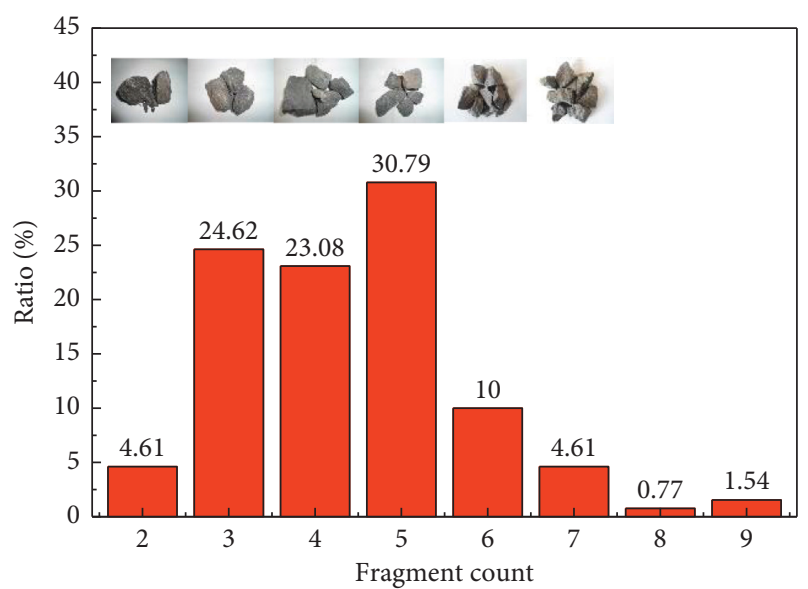

FIgURE 7: Ratio distribution of fragment count.

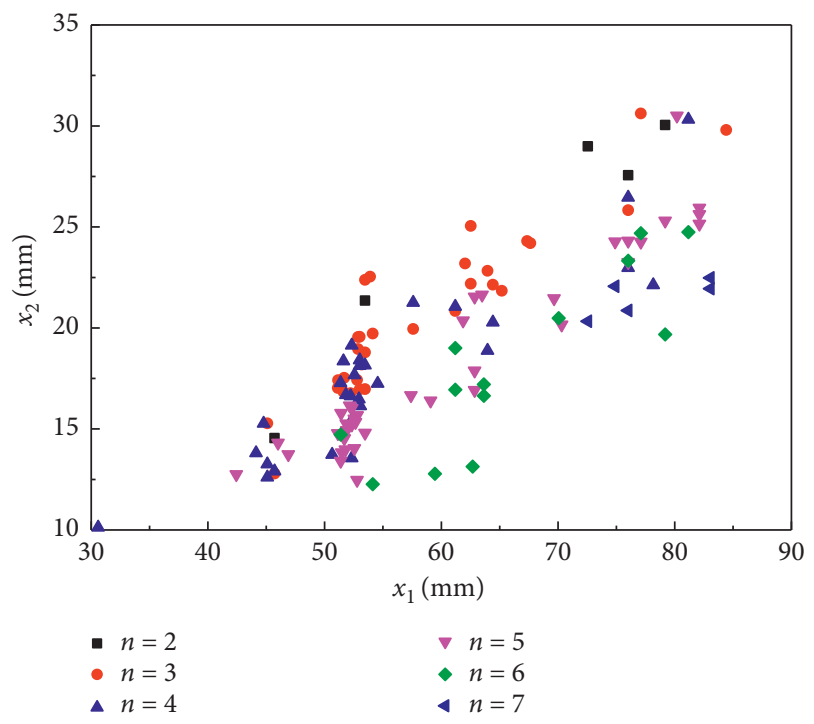

FIGURE 8: Size change before and after impact breakage.

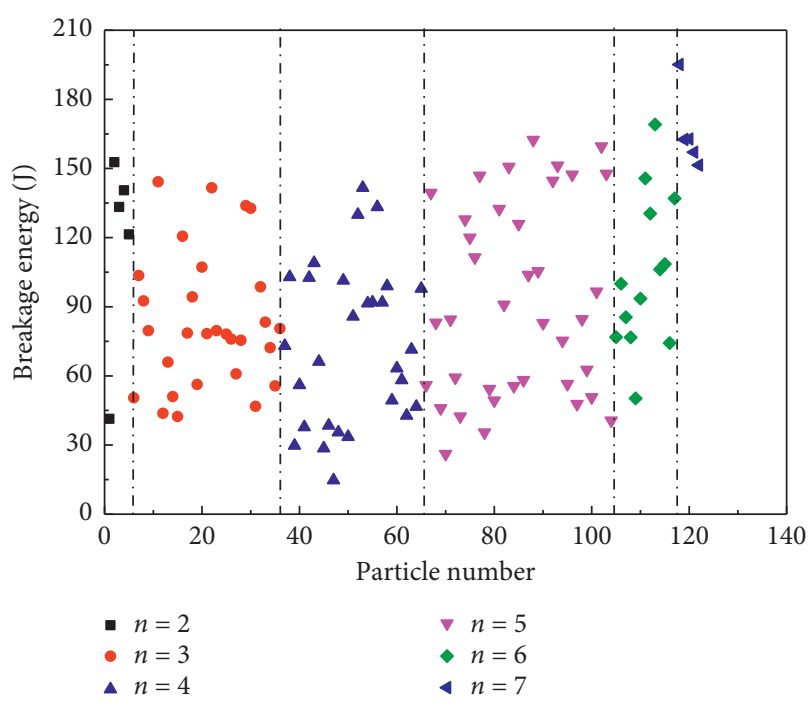

FIGURE 9: Breakage energy of each particle. tensile fracture occurred, and fractures on the sample surface became $\mathrm{V}$ shaped.

Figure 10(b) shows that the upper end contacted the hammer at the vertex, and then the contact part was smashed, enlarging the contact area. Sample S17 was deflected, decreasing the contact area of the lower end with the baseplate. The stress in the sample was concentrated. The force centre at the two ends moved to the same vertical plane, and the tensile fracture expanded from the upper end to lower end.

Figure 10(c) shows that the upper end bore face loading, the contact area increased, four vertexes came into contact with the baseplate, and the contact points were crushed to form face loading; tensile fractures with small width occurred at the centre part of sample SQ87 during impact, a small amount of debris was produced at the impact part, and a few small fragments were produced at the right-hand part of the sample.

Sample S16 in Figure 10(d) took on a triangular shape with an upper concave arc, and the loading mode of the upper end converted from vertex loading to face loading, but the contact area was very small; the vertex loading at the lower end converted to be combined loading mode containing vertex loading and face loading, and the tensile fracture expanded, declining upward from the left-hand side of the arc.

Figure 10(e) shows that sample SQ90 bore vertex loading at the upper end and multivertex loading at the lower end; a large degree of deflection occurred during impact, the contact area became larger at the upper end, the contact vertexes vanished at the left-hand side of the lower end, and then face loading occurred; multitensile fractures were brought about from the left-hand side to the right-hand side of the sample and expanded upward from the lower end.

Above all, the irregular particles cannot maintain a contact mode with the hammer and baseplate because the vertex loading or line loading converts to face loading at the upper end before macroscopic fracture, and multimodes of loading occur at the lower end according to ore shape and deflection degree. Face loading is helpful for ore breakage. The main breakage pattern is tensile fracture because the tensile strength is much lower than compression strength, and the sample converts from an unstable state to the state at which tensile fracture occurs easily.

\subsubsection{Relationship between Loading Mode and Specific} Breakage Energy. It can be seen from Figures 10(a)-10(c) that the loading mode significantly affects the specific breakage energy with the same number of fragments and approximate ore mass. The sphericity of sample SQ89 is 3\% different from that of sample S17, which shows that the irregularity of the two is close to each other, but the difference in specific energy is 32\%. SQ89 consumed less energy because of the small smashing degree at the part of line loading; S17 consumed more energy because the smashing degree is larger at the part of vertex loading and the impact time is prolonged. The shape of SQ87 is irregular massive; it is difficult to bring about tensile fracture, and the crushing 

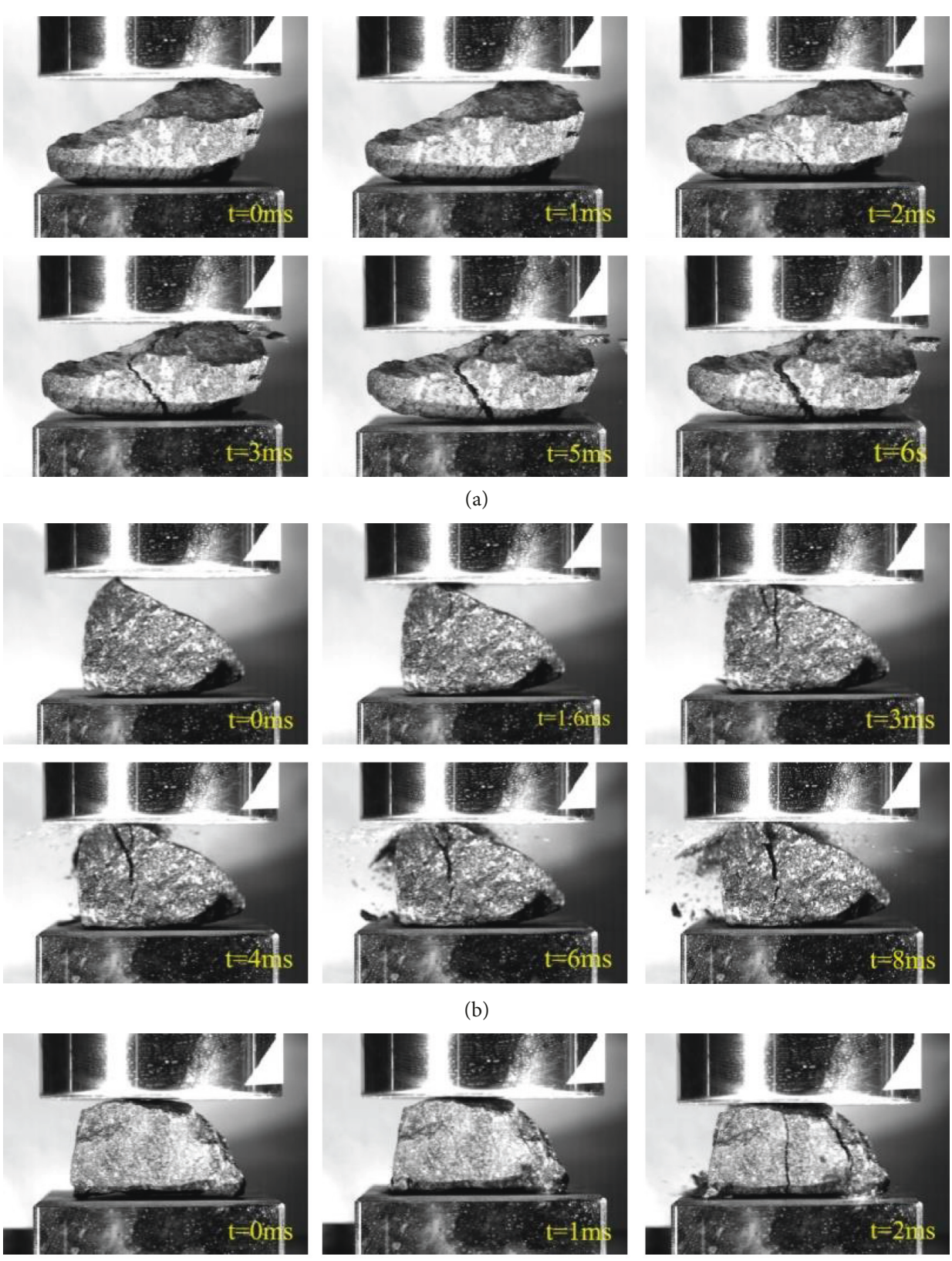

(b)
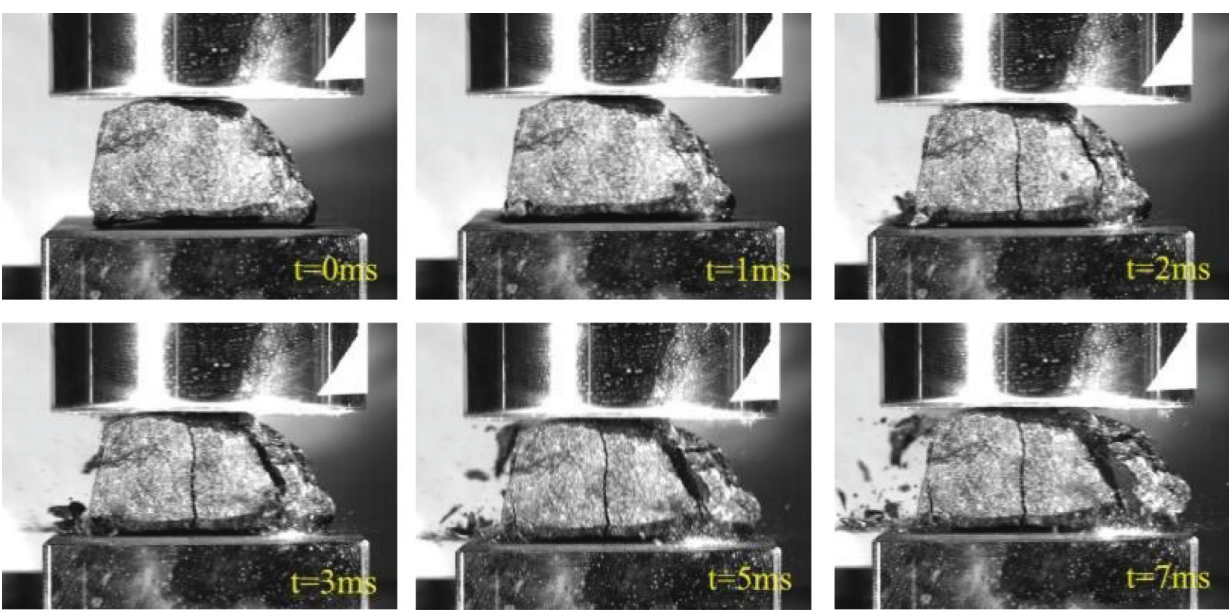

(c)

FIgure 10: Continued. 

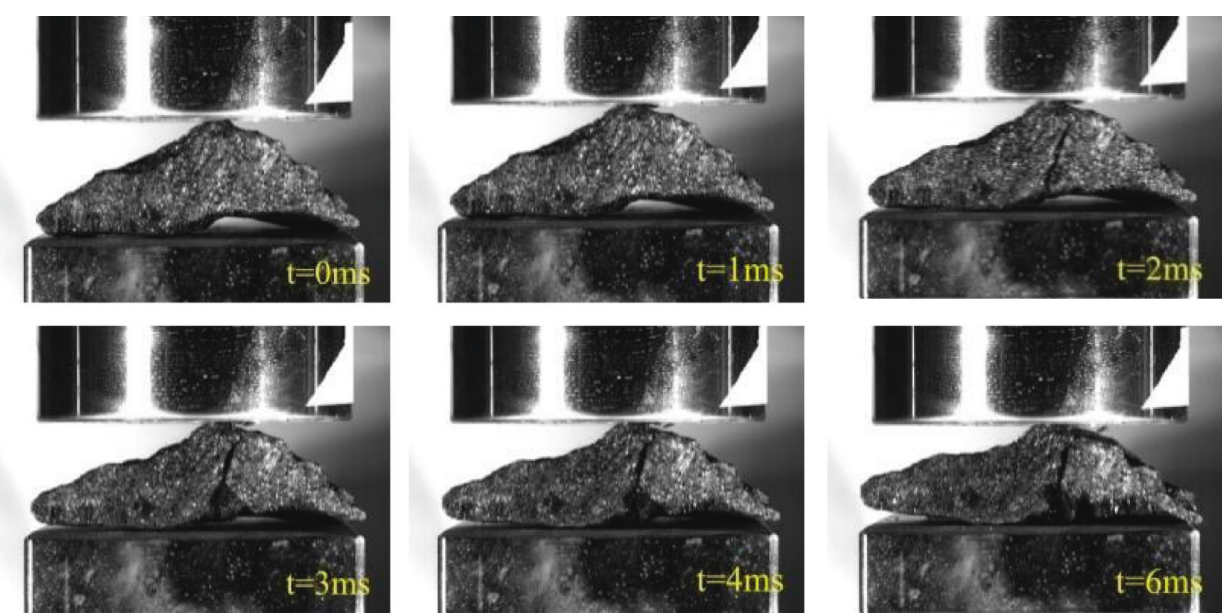

(d)
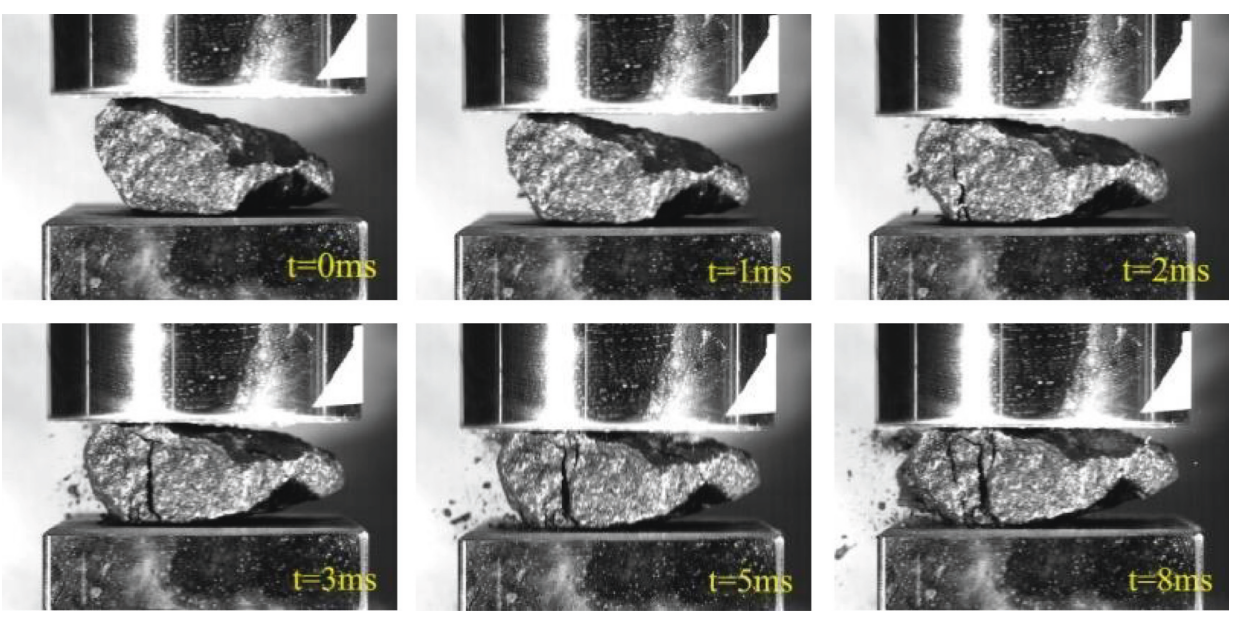

(e)

FIGURE 10: Photographs of impact breakage process recorded by high-speed camera. (a) Sample code is SQ89, mass is $259 \mathrm{~g}$, sphericity is 0.64 , specific breakage energy is $169 \mathrm{~J} / \mathrm{kg}$, and fragment number is three. (b) Sample code is S17, mass is $265 \mathrm{~g}$, sphericity is 0.66 , specific breakage energy is $248.7 \mathrm{~J} / \mathrm{kg}$, and fragment number is three. (c) Sample code is SQ87, mass is $256 \mathrm{~g}$, sphericity is 0.74 , specific breakage energy is $305.1 \mathrm{~J} /$ $\mathrm{kg}$, and fragment number is three. (d) Sample code is S16, mass is $232 \mathrm{~g}$, sphericity is 0.579 , specific breakage energy is $128.4 \mathrm{~J} / \mathrm{kg}$, and fragment number is four. (e) Sample code is SQ90, mass is $260 \mathrm{~g}$, sphericity is 0.74 , specific breakage energy is $223.7 \mathrm{~J} / \mathrm{kg}$, and fragment number is five.

degree of the bulge at the lower end is greater, which consumes higher specific energy than SQ89 and S17.

According to the comparison between Figures 10(a) and 10(d), the crushing degrees of contact parts of SQ89 and S16 with the hammer and bottom plate are small. The place state of S16 forms the loading mode of a cantilever, which makes it easy to fracture through tensile stress; it has a higher fragmentation degree even though it consumes less energy.

Figures $10(\mathrm{~b})$ and 10(e) show that the upper ends of S17 and SQ90 bear vertex loading, the upper end of S17 bears face loading after smashing the contact part, and then tensile fracture occurs and S17 deflects on a small scale. SQ90 bears face loading after deflection; it has significant tensile fracture, and then the upper end is smashed; the breakage degree of SQ90 under lower specific energy is much higher than that of S17.

Figures 10(c) and 10(e) show that the crushing degrees differ from each other greatly, even though the sphericities of the two samples are the same; the mass difference is only
$1.5 \%$ and the initial loading modes are similar. During impact, SQ87 does not deflect, but SQ90 deflects to the state in which it is easy to bring about tensile fracture; the specific breakage energy of SQ90 is 0.73 times that of SQ87, but SQ90 has a higher crushing degree.

Above all, the loading mode has great influence on specific breakage energy during the impact breakage process; specific energy is mostly consumed under vertex loading. The larger the initial loading area is, the smaller the scale on which the contact part is smashed in the early stage of the crushing process, and the less energy that is consumed for fragmentation. The shape or placement state that is conductive to tensile fracture can help reduce the specific energy that is needed in fragmentation.

3.3. Shape Factor and Specific Energy. As with one specific kind of ore from one specific place, mineral composition and inner structure change little in different samples; a 
hypothesis could be proposed that the influence of mineral composition and inner structure can be ignored because the effect of shape on breakage is greater than that of mineral composition and inner structure [13]. Because samples of the same size were difficult to collect, the difference in the particle sizes of magnetite ore was fixed at $5 \%$ to analyze the effect of shape on specific breakage energy and to establish the quantitative relationship between shape parameter and specific breakage energy.

The experimental data with the same fragment numbers were chosen to plot the scatter graphs of particle sphericity and specific breakage energy. The fragment numbers three, four, and five are shown in Figure 11. The linear relationship between sphericity and specific breakage energy was fitted, which shows that specific breakage energy increases with increasing sphericity. The particle consumes more specific breakage energy if the shape is closer to spherical because the probability of vertex loading is higher. Zheng et al. [11] pointed out that the sphere particle bearing vertex loading bears smallest maximum wall force and has a lower breakage degree compared with face loading and edge loading when the velocity is $16 \mathrm{~m} / \mathrm{s}$. Zhou et al. [10] found that the integrity of particles is higher after impact if the particle shape is closer to spherical.

Sphericity describes the shape of particles, such as spheres, cubes, and elongated or flaky shape, and it is an index of the irregularity of particles. Afshar et al. [13] used waste rocks, recycled concreted aggregate, and crushed brick to carry out single-particle crushing tests, showing that the average yielding points of bulky particles with sphericities ranging from 0.8 to 0.84 are $2.45,3.32$, and 2.9 times that of elongated particles with sphericities ranging from 0.7 to 0.71 , and the vertical displacements of bulky particles are much larger than those of elongated particles. It can be concluded that the bulky particles with higher sphericity consume more energy to be fragmented than the elongated particles with smaller sphericity. The work by Tavares and King [7] also indicated that the strength and stiffness of particles decrease with more irregular particle shape. It can be inferred that shape influences the breakage energy by changing the mechanical properties of irregular particles. In addition, if the shape of ore is more irregular, tensile fracture is easier to achieve. Because the tensile strength of magnetite is only one-tenth the compression stress, the energy consumed in tensile fracture is much less than that consumed in compression breakage.

It can be seen that the specific breakage energy of particles with smaller sphericity is smaller when the particle size is fixed within a small range. According to the fitting results of specific breakage energy and sphericity, an empirical formula for the two is proposed as follows:

$$
e_{\mathrm{m}}=k_{1}+k_{2} \psi
$$

where $e_{\mathrm{m}}$ is specific breakage energy $(\mathrm{J} / \mathrm{kg}), k_{1}$ and $k_{2}$ are coefficients, and $\psi$ is the sphericity.

3.4. Initial Size of Ore and Specific Breakage Energy. The relationship between specific breakage energy and particle size is analyzed from the aspect of energy theory of ore breakage. According to the size-dependent breakage model provided by Shi and Kojovic [30], the equation of specific energy that is required to crush ore from size $d$ to the degree of $t_{10}$ can be induced as follows [31, 32]:

$$
E_{\mathrm{cs}}=\frac{\ln \left(1-t_{10} / M\right)}{-3.6 p \cdot d^{(1-q)}},
$$

where $E_{\mathrm{cs}}$ is specific energy $(\mathrm{kW} \cdot \mathrm{h} / t) ; t_{10}$ is the cumulative percentage of product passing one-tenth of the initial particle size (\%); $M, p$, and $q$ are fitting constants from a set of breakage test data; and $d$ is the initial size of particle ( $\mathrm{mm})$. The value of $q$ is within $(0,1)$ in most cases.

It can be seen from equation (13) that the relationship of specific breakage and initial size can be expressed in equation (14) with the fixed breakage index $t_{10}$. With the increase in the initial size of a particle, the specific breakage energy needed decreases according to the power formula:

$$
E_{\mathrm{cs}} \propto d^{-m}
$$

where $m$ is the fitting index $(1<m<2)$.

Equation (14) is in accordance with the theoretical relationship in equation (15) proposed by Nagahama [33]. If the exponent $D$ in equation (15) is set to the values $3,2.5$, and 2 , the relationship of specific energy and initial size meets Kick energy theory [34], Bond energy theory [17], and Von Rittinger energy theory [35], respectively:

$$
E \propto r^{D-3}
$$

where $E$ is breakage energy per unit mass for fracturing $(\mathrm{J} / \mathrm{kg})$, $r$ the initial size of the brittle particle $(\mathrm{mm})$, and $D$ the fractal dimension of fracture surface $(2<D<3)$. Gutsche and Fuerstenau [36] broke irregular rock within a rigidly mounted roll mill and put forward a similar relationship between specific breakage energy and average initial size of feed.

According to the former studies, we believe that there exists a relationship with the power formula between the initial size of ore and specific breakage that is needed to crush the ore particle to some degree:

$$
e=c r^{-k}, \quad(0<k<1) \text {. }
$$

To analyze the effect of initial size of ore particles on specific breakage energy, the experimental data were chosen, and the difference in sphericity is limited to $10 \%$. The scatter graphs of initial size and breakage energy were plotted, and the relationship of the two is fitted with equation (16), which is shown in Figure 12. The fragment numbers are three, four, and five, respectively, in Figure 12 as well. The fitting results prove that the relationship between initial size and breakage energy meets a negative power formula. With the increase of the initial size of particles, the specific breakage energy decreases, in agreement with the test result with quartz and limestone in the work by King and Bourgeois [19]. Tavares and King [7] insisted that the fracture energy is sensitive to particle structure such as critical cracks and flaws in highstress zones in the material. The decrease in the size of particles leads to the decrease in the size of the largest microcrack, which results in the larger specific fracture 


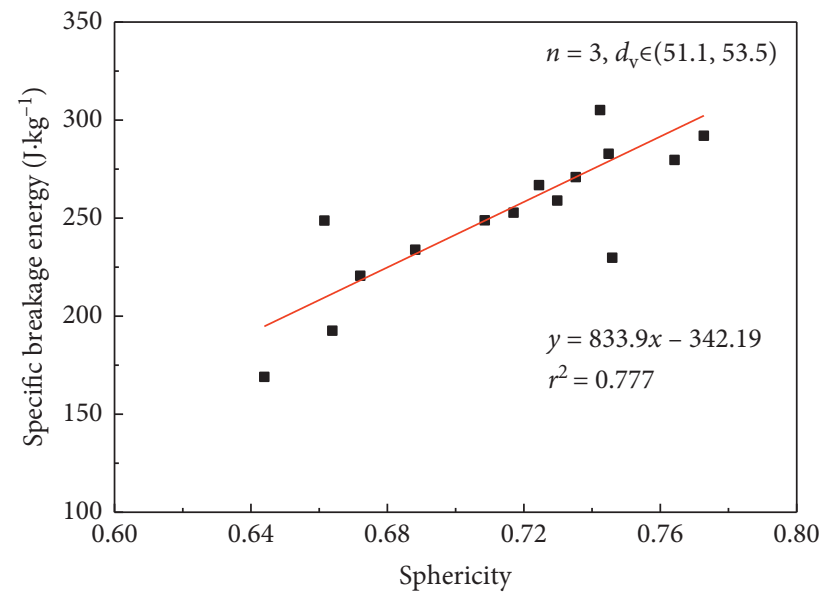

(a)

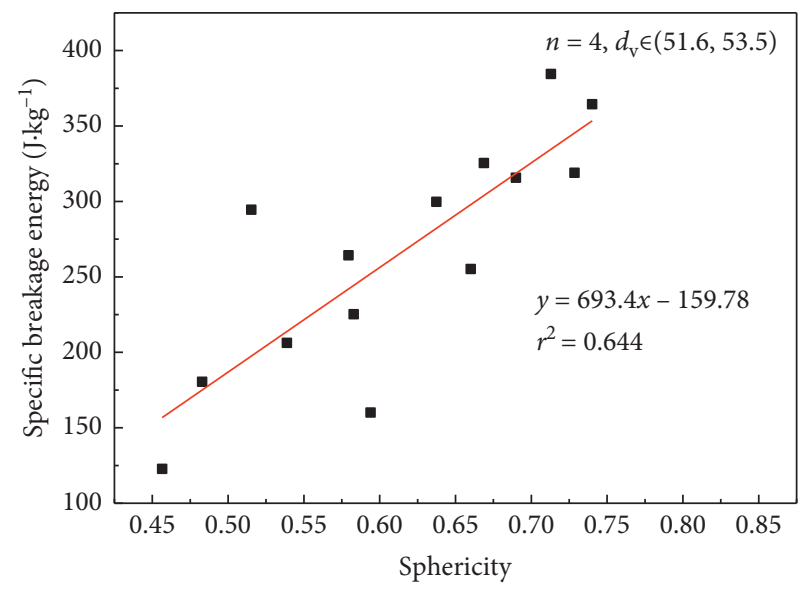

(b)

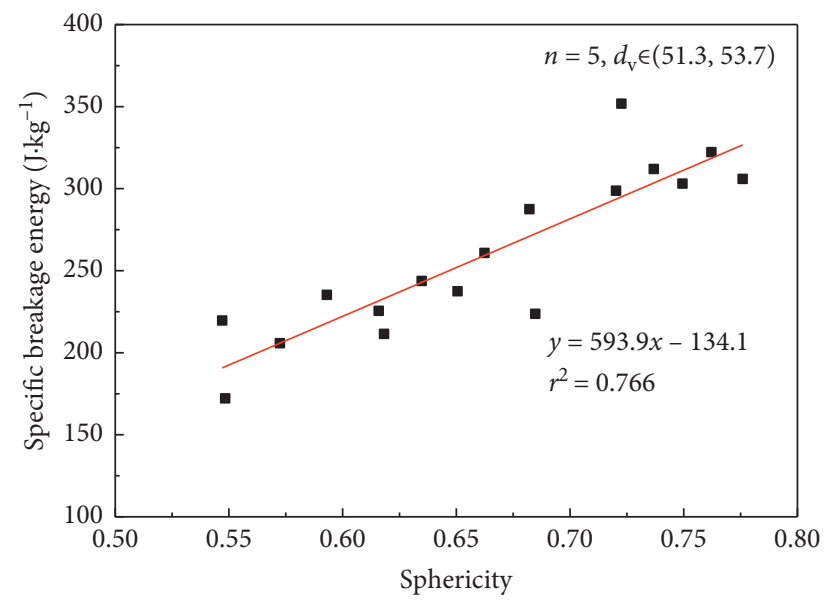

(c)

FIGURE 11: Relationship between specific breakage energy and sphericity.

energies at smaller particle sizes, and the relationship between particle size and mass-specific fracture energy can be described by a power law derived from Hertzian contact theory and Weibull's weakest link criterion.

The studies by Banini [22] and Shi [31, 32] can also support the relationship between specific breakage energy and particle size. The specific breakage energy that is needed to crush ore to some degree depends on the ore competence indicator $(A \cdot b)$. According to the database of ore breakage, the larger the value of $(A \cdot b)$ is, the less energy the fragmentation of ore consumes per unit mass. The study by Taşdemir [37] showed that larger particles are easier to crush than smaller particles because the fragmentation probability rises with increasing particle size.

The empirical relationship between specific breakage energy and initial size of irregular magnetite ore is expressed by equation (17). The indexes in the fitted formula in Figure 10 are on average $-0.5(-0.521$ for $n=3,-0.402$ for $n=4$, and -0.588 for $n=5$ ), which indicates that the relationship between specific breakage energy and initial size meets equation (15) when $D$ equals 2.5 :

$$
e_{\mathrm{m}}=c d_{\mathrm{v}}^{-0.5} \text {, }
$$

where $c$ is the fitting constant and $d_{\mathrm{v}}$ the initial size of ore $(\mathrm{mm})$.

3.5. Comprehensive Relationship among Specific Breakage, Energy Shape, and Size. According to the quantitative relationship among specific breakage energy, sphericity, and initial size of magnetite ore, a model is proposed to express the comprehensive effect of size and shape on specific breakage energy, which is expressed by

$$
e_{\mathrm{m}}=z_{1} d^{-0.5}+z_{2} \psi-q,
$$

where $z_{1}$ represents size constants, $z_{2}$ is a shape constant, and $q$ is an energy constant.

The data from experiments whose fragment numbers are three, four, and five were fitted with equation (18). The fitted results are listed in Table 1, showing that the shape and initial size of particles have obvious effects on specific breakage energy jointly. The formulas are listed in Table 1, the coefficients of magnetite particle size and sphericity are positive numbers, and the exponent of magnetite particle size is -0.5 , which shows that the specific breakage energy increases with decreasing particle size and increasing sphericity at the 


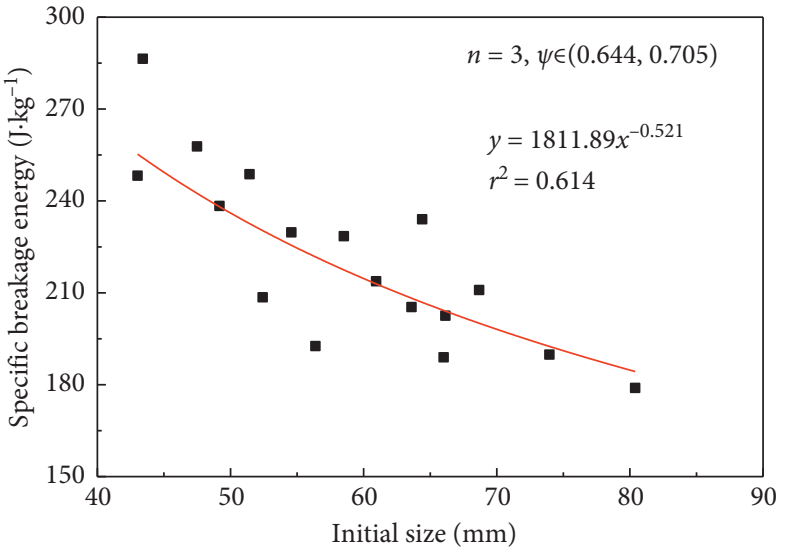

(a)

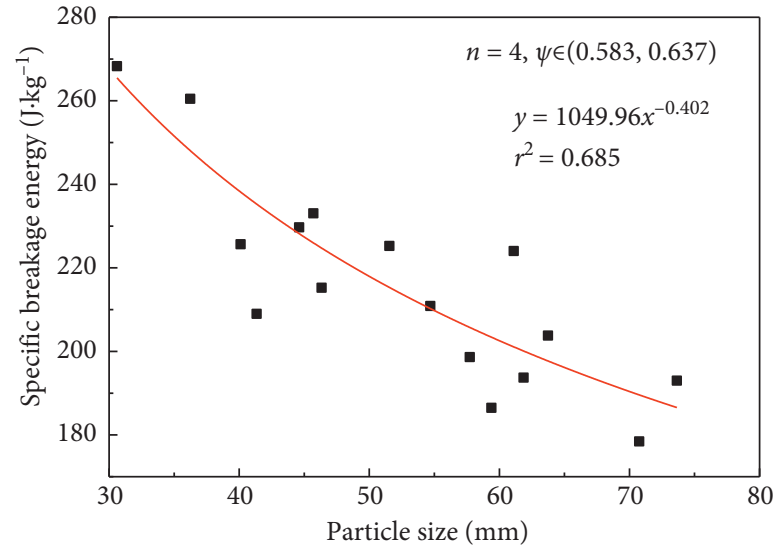

(b)

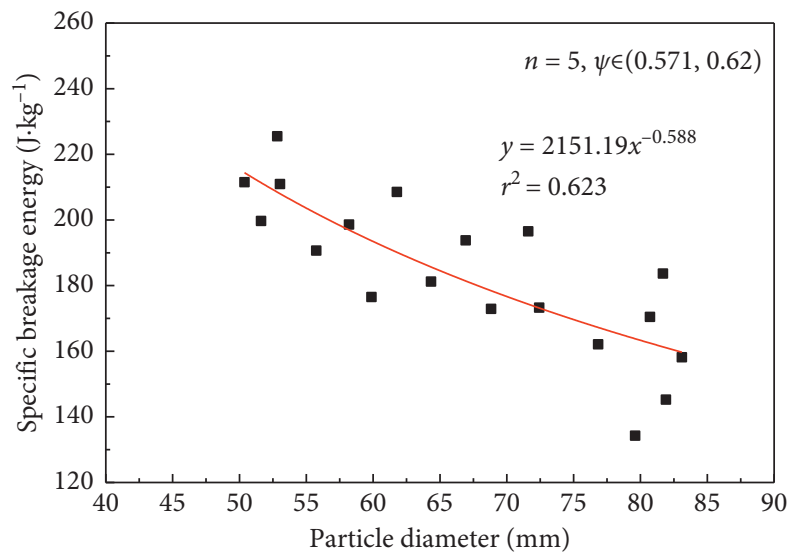

(c)

FIgURE 12: Relationship between specific breakage energy and initial size.

same time. The irregular particles with lower sphericity on the anvil tend to convert and have tensile fracture resulting in smaller specific energy consumed in breakage. Unland and Al-Khasawneh [15] found that reduction of the collision velocity caused by the orientation phase during impact reduces transferred energy of irregular particles. Larger particles require smaller specific energy for fracture because of a smaller crack density per unit volume [22]. The massspecific crushing energy and particle sizes have a reduction relationship in a power law [38]. Therefore, the greater irregularity and larger initial size of particles are all helpful for particle fragmentation with smaller specific energy.

The specific breakage energy of particles determines the estimation of minimum energy consumption in comminution according to Tavares [6], and it is significantly affected by size and shape; hence, the dual effects of shape and initial size should be considered in the study of the characteristics of breakage energy of irregular particles in response to individual impacts.

According to the comprehensive relationship model of specific breakage energy, sphericity, and initial size, if the feed in practice has a more irregular shape and larger initial size, the input power could be reduced to decrease energy consumption per unit mass of ore and improve energy efficiency if the size distribution of fragments is fixed. During ore dressing, specific breakage energy rises rapidly with decreasing ore size [39]. The production capacity of flaky, acicular, or long columnar fragments should be improved to reduce the sphericity of the product in the former breakage stage through the optimization of the crushing machinery or breakage method. Then, it is possible to reduce the specific breakage energy consumed by ore particles with smaller sizes in the later stage, and the energy efficiency in the later breakage stage can hopefully be improved under the condition that the particle size distribution of two adjacent stages is fixed.

Narrow-size particles were broken into several fragments under drop weight tests to have the same breakage degree for establishing the quantitative relationship among specific breakage energy, sphericity, and initial size, so further study considering fragment size distribution will be done with a wider range of initial particle sizes to provide more detailed guidance for reducing mass-specific breakage energy and improving energy efficiency in mechanical crushing.

\section{Conclusions}

In the present study, we attempted to reveal the effect of shape and initial size of irregular particles on specific breakage energy. Impact experiments of single-particle breakage were carried out with a modified DWT to 
TABLE 1: Comprehensive relationship of specific breakage energy, sphericity, and initial size.

\begin{tabular}{lcc}
\hline Fragment number & Comprehensive relationship & Correlation coefficient \\
\hline 3 & $e_{\mathrm{m}}=1684.01 d_{\mathrm{v}}^{-0.5}+30 \psi-2.66$ & 0.604 \\
4 & $e_{\mathrm{m}}=1044.79 d_{\mathrm{v}}^{-0.5}+228.11 \psi-72$ & 0.59 \\
5 & $e_{\mathrm{m}}=1162.1 d_{\mathrm{v}}^{-0.5}+164.4 \psi-24.06$ & 0.606 \\
\hline
\end{tabular}

measure the effective specific breakage energy of irregular magnetite ore. Magnetite ore with different shapes had different loading modes and different breakage processes. A significant relationship exists among ore sphericity, initial size, and specific breakage of irregular ore. The main conclusions are summarized as follows:

(1) Face loading is helpful to the breakage of irregular particles, the main breakage style is tensile fracture, and the samples that are not placed stably convert to the state in which it is easy to bring about tensile fracture. The specific breakage energy is lower if the initial loading area is larger or the shape or placement state of particles is more conducive to tensile fracture.

(2) The specific breakage energy has a linear relationship with the sphericity of irregular particles; the specific breakage energy increases with increasing sphericity, which indicates a more regular shape of particles, e.g.,bulky particles. The relationship between initial particle size and specific breakage energy is a power function with an exponent of -0.5 ; with increasing initial particle size, the specific breakage energy decreases.

(3) The specific breakage energy of irregular particles is affected by both shape and initial size. The comprehensive relationship among specific breakage energy, sphericity, and initial size is established based on the experimental results. The design of input power of the crushing machinery and the optimization of crushing technology should be performed considering the influences of shape and initial size of particles to reduce specific energy consumption during ore processing, and further study is still required to provide more detailed guidance.

\section{Data Availability}

The experimental data used to support the findings of this study are available from the corresponding author upon request. On the other hand, some data have been included within the article, such as property parameters of magnetite ore, the sphericity and initial size of samples, the mass of the hammer, the fragment number, specific breakage energy in Figure 10, etc.

\section{Conflicts of Interest}

The authors declare that they have no conflicts of interest.

\section{Acknowledgments}

The National Natural Science Foundation of China (grant nos. 51374087 and 51774137) is acknowledged for its financial support. The authors thank LetPub (http://www. LetPub.com) for its linguistic assistance during the preparation of this manuscript.

\section{References}

[1] S. Martins, "Size-energy relationship in comminution, incorporating scaling laws and heat," International Journal of Mineral Processing, vol. 153, pp. 29-43, 2016.

[2] Ö. Genç, A. H. Benzer, and Ş. L. Ergün, "Analysis of single particle impact breakage characteristics of raw and HPGRcrushed cement clinkers by drop weight testing," Powder Technology, vol. 259, pp. 37-45, 2014.

[3] W. Zuo and F. Shi, "Ore impact breakage characterisation using mixed particles in wide size range," Minerals Engineering, vol. 86, pp. 96-103, 2016.

[4] F. Saeidi, M. Yahyaei, M. Powell, and L. M. Tavares, "Investigating the effect of applied strain rate in a single breakage event," Minerals Engineering, vol. 100, pp. 211-222, 2017.

[5] L. M. Tavares, "Energy absorbed in breakage of single particles in drop weight testing," Minerals Engineering, vol. 12, no. 1, pp. 43-50, 1999.

[6] L. M. Tavares, "Optimum routes for particle breakage by impact," Powder Technology, vol. 142, no. 2-3, pp. 81-91, 2004.

[7] L. M. Tavares and R. P. King, "Single-particle fracture under impact loading," International Journal of Mineral Processing, vol. 54, no. 1, pp. 1-28, 1998.

[8] T. J. Napier-Munn, S. Morrell, and Morrison, Mineral comminuion circuits: their operation and optimisation, Julius Kruttschnitt Mineral Research Centre, Queensland, Australia, 1996.

[9] T. G. Viscarra, E. M. Wightman, N. W. Johnson, and E. V. Manlaping, "The effect of breakage method on the shape properties of an iron-oxide hosted copper-gold ore," Minerals Engineering, vol. 24, no. 13, pp. 1454-1458, 2011.

[10] J.-W. Zhou, Y. Liu, C.-L. Du, and S.-Y. Liu, "Effect of the particle shape and swirling intensity on the breakage of lump coal particle in pneumatic conveying," Powder Technology, vol. 317, pp. 438-448, 2017.

[11] K. Zheng, C. Du, J. Li, B. Qiu, L. Fu, and J. Dong, "Numerical simulation of the impact-breakage behavior of non-spherical agglomerates," Powder Technology, vol. 286, pp. 582-591, 2015.

[12] L. Liu, K. D. Kafui, and C. Thornton, "Impact breakage of spherical, cuboidal and cylindrical agglomerates," Powder Technology, vol. 199, no. 2, pp. 189-196, 2010.

[13] T. Afshar, M. M. Disfani, A. Arulrajah, G. A. Narsilio, and S. Emam, "Impact of particle shape on breakage of recycled construction and demolition aggregates," Powder Technology, vol. 308, pp. 1-12, 2017.

[14] P. Yan, Z. Y. Dong, Q. Fang, and Y. D. Zhang, "Numerical simulation of the effects of falling rock's shape and impact pose on impact force and response of RC slabs," Construction and Building Materials, vol. 160, pp. 497-504, 2017.

[15] G. Unland and Y. Al-Khasawneh, "The influence of particle shape on parameters of impact crushing," Minerals Engineering, vol. 22, no. 3, pp. 220-228, 2009. 
[16] A. Norraziah, S. H. S. Faud, and M. H. M. Hazizan, "The effect of size and shape on breakage characteristic of mineral," in Proceedings of the 5th International Conference on Recent Advances in Materials, Minerals and Environment, Procedia Chemistry, vol. 19, pp. 702-708, University Science Malaysia, Malaysia, 2016.

[17] F. C. Bond, "Crushing and grinding calculations," British Chemical Engineering Part I, vol. 6, no. 6, pp. 378-385, 1961.

[18] J. A. Holmes, "A contribution to the study of comminution: a modified form of Kick's law," Transactions of the Institution of Chemical Engineers (London), vol. 35, p. 125, 1957.

[19] R. P. King and F. Bourgeois, "Measurement of fracture energy during single particle fracture," Minerals Engineering, vol. 6, no. 4, pp. 363-367, 1993.

[20] S. Morrell, "An alternative energy-size relationship to that proposed by bond for the design and optimisation of grinding circuits," International Journal of Mineral Processing, vol. 74, no. 1-4, pp. 133-141, 2004.

[21] D. R. Walker and M. C. Shaw, "A physical explanation of the empirical laws of comminution," AIME Transactions, vol. 199, pp. 313-320, 1954.

[22] G. A. Banini, An integrated description of rock breakage in comminution machines, Ph.D. thesis, University of Queensland (JKMRC), Brisbane, Australia, 2000.

[23] E. J. Garboczi, K. A. Riding, and M. Mirzahosseini, "Particle shape effects on particle size measurement for crushed waste glass," Advanced Powder Technology, vol. 28, no. 2, pp. 648657, 2017.

[24] Y. Sun and C. Zheng, "Breakage and shape analysis of ballast aggregates with different size distributions," Particuology, vol. 35, pp. 84-92, 2017.

[25] E. R. Cunha, P. P. S. Cavalcanti, F. Saeidi, and L. M. Tavares, "On the limitation of using the JKRBT in investigating incremental breakage," Minerals Engineering, vol. 118, pp. 3336, 2018.

[26] D. J. Reddish, R. L. Stace, P. Vanichkobinda, and D. N. Whittles, "Numerical simulation of the dynamic impact breakage testing of rock," International Journal of Rock Mechanics \& Mining Sciences, vol. 42, no. 2, pp. 167-176, 2015.

[27] V. Rizmanoski, "The effect of microwave pretreatment on impact breakage of copper ore," Minerals Engineering, vol. 24, no. 14, pp. 1609-1618, 2011.

[28] B. Benjamin, "Quantifying of impact breakage of cylindrical rock particles on an impact load cess," International Journal of Mineral Processing, vol. 161, pp. 1-6, 2017.

[29] H. Nagahama and K. Yoshii, "Fractal dimension and fracture of brittle rocks," International Journal of Rock Mechanics and Mining Sciences \& Geomechanics Abstracts, vol. 30, no. 2, pp. 173-175, 1993.

[30] F. Shi and T. Kojovic, "Validation of a model for impact breakage incorporating particle size effect," International Journal of Mineral Processing, vol. 82, no. 3, pp. 156-163, 2007.

[31] F. Shi, "A review of the applications of the JK size-dependent breakage model," International Journal of Mineral Processing, vol. 155, pp. 118-129, 2016.

[32] F. Shi, "A review of the applications of the JK size-dependent breakage model part 2: assessment of material strength and energy requirement in size reduction," International Journal of Mineral Processing, vol. 157, pp. 36-45, 2016.

[33] H. Nagahama, "Fractal fragment size distribution for brittle rocks," International Journal of Rock Mechanics and Mining Sciences \& Geomechanics Abstracts, vol. 30, no. 4, pp. 469-471, 1993.
[34] F. Kick, Das Gesetz der Proportionalen Widerstande und seine Anwendung Felix, Verlag von Arthur Felix, Leipzig, Germay, 1885.

[35] P. R. Von Rittinger, Lehrbuch der Aufbereitungskunde, Ernst and Korn, Berlin, Germany, 1867.

[36] O. Gutsche and D. W. Fuerstenau, "Influence of particle size and shape on the comminution of single particles in a rigidly mounted roll mill," Powder Technology, vol. 143-144, pp. 186-195, 2004.

[37] A. Taşdemir, "Fractal evaluation of particle size distributions of chromites in different comminution environments," Minerals Engineering, vol. 22, no. 2, pp. 156-167, 2009.

[38] Y. F. Xu and Y. D. Wang, "Size effect on specific energy distribution particle commimution," Fractals, vol. 25, no. 2, article 1750016, 2017.

[39] R. T. Hukki, "Proposal for a solomnic settlement between the theories of Von Rittinger, Kick and Bond," AIME Transactions, vol. 223, pp. 403-408, 1962. 


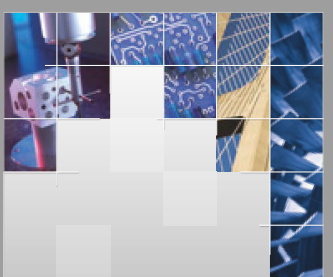

\section{Enfincering}
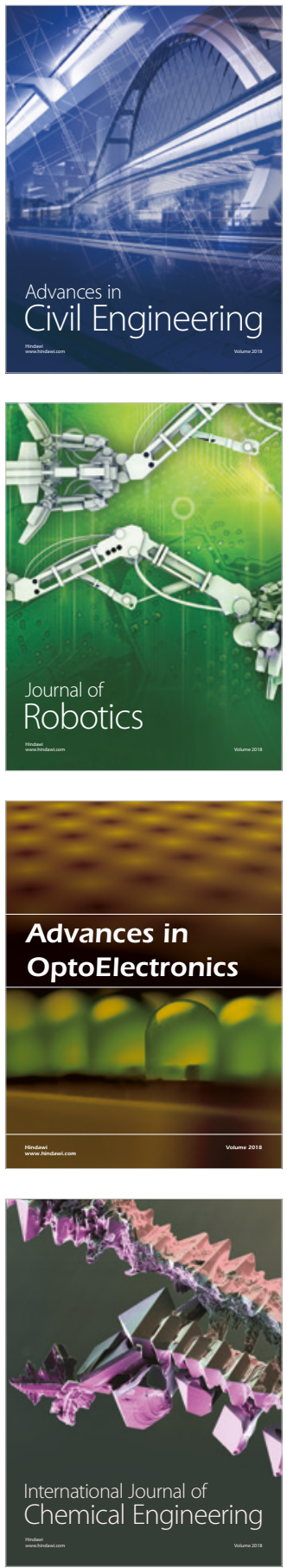

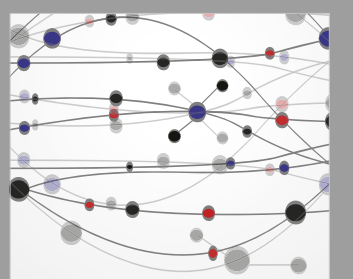

\section{Rotating \\ Machinery}

The Scientific World Journal

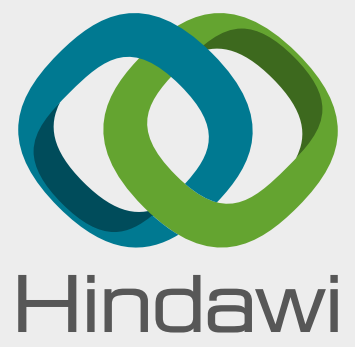

Submit your manuscripts at

www.hindawi.com
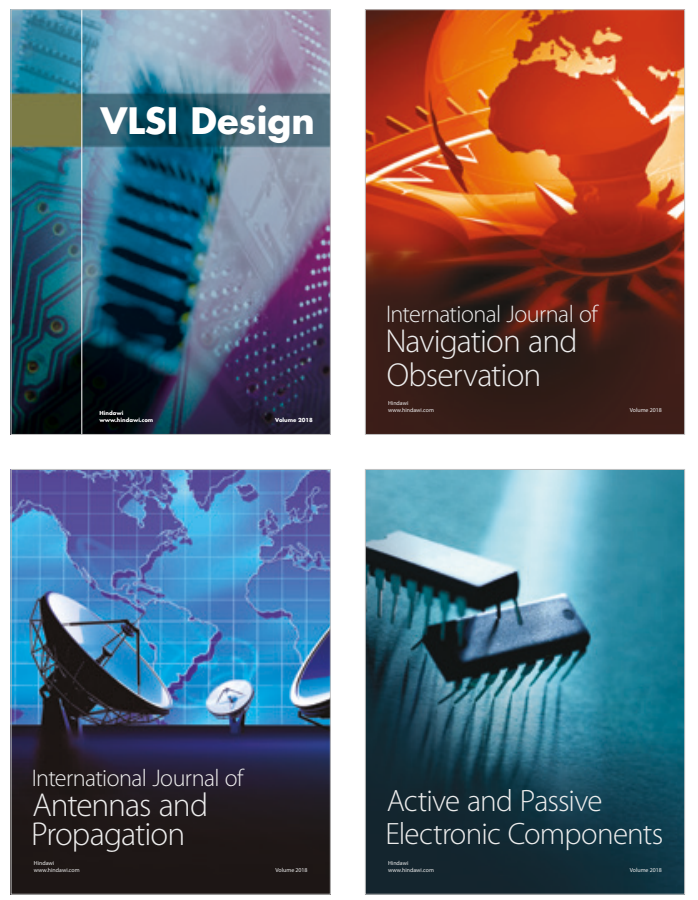
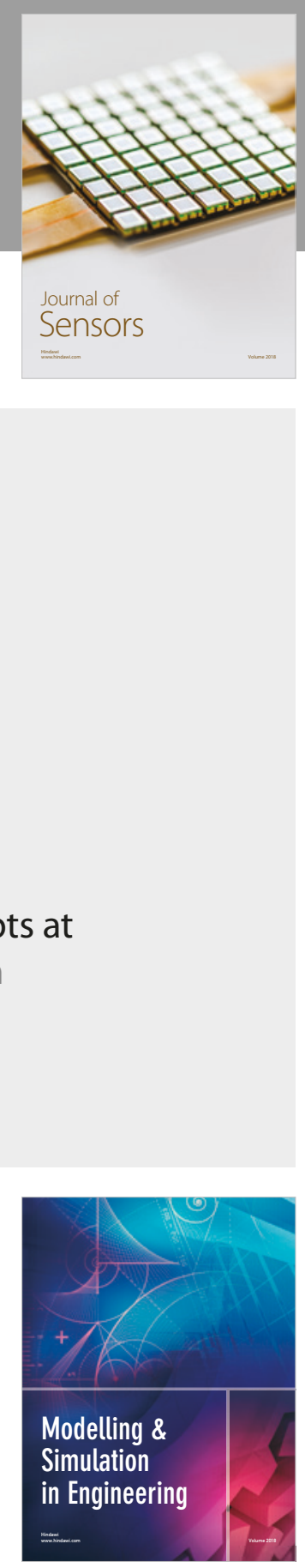

\section{Advances \\ Multimedia}
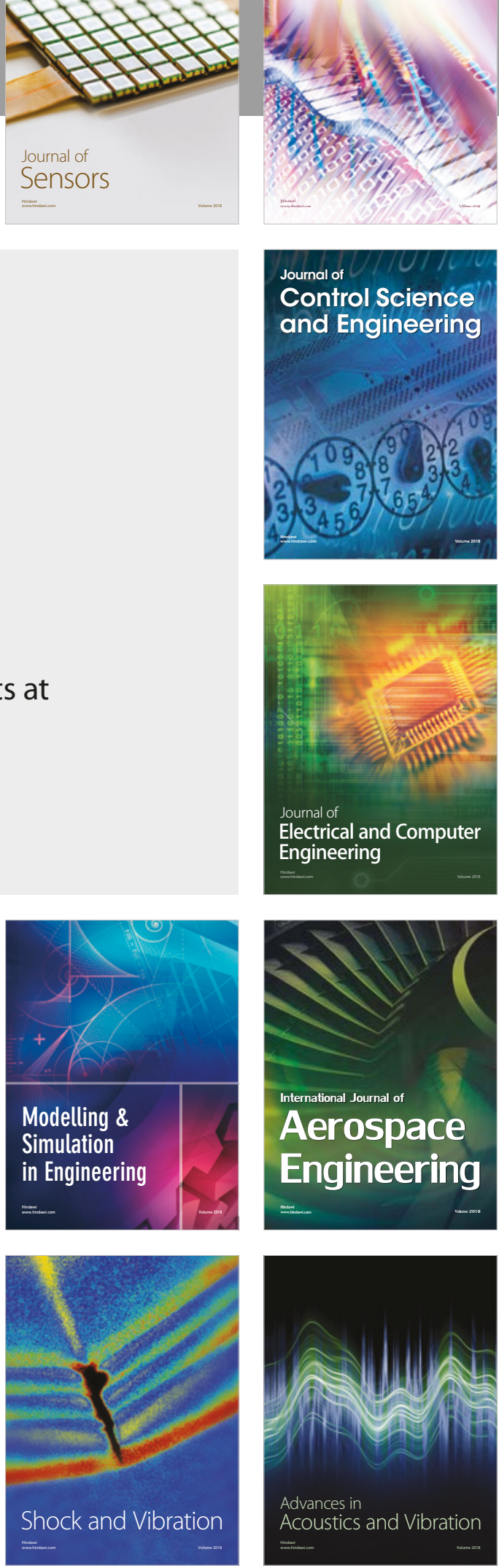